\title{
Literatura e espaço digital: diálogos poéticos
}

\author{
Angela Guida \\ Universidade Federal de Mato Grosso do Sul
}

Resumo: Este artigo tem por objetivo estabelecer uma reflexão acerca das relaçôes entre literatura e novas tecnologias, sobretudo a literatura produzida no espaço digital, em seu projeto de reinvenção da linguagem literária, em que recursos como programas de computador fazem parte do processo criativo. Palavras-chave: literatura, diálogo, digital.

\begin{abstract}
Não se trata de criar como um computador, mas de criar com. De colocar o computador a serviço da produção poética. De servir-se de seus programas para inscrever signos. E isso nada tem a ver, necessariamente, com maquinolatria, tecnolatria ou cienciolatria. Ao contrário, trata-se de "conectar" as novas tecnologias signicas com o cerne mesmo da bumanidade.
\end{abstract}

RISÉRIO, 1998, p. 203, grifos do autor.

$E_{\mathrm{m}}$ O espaço literário, Maurice Blanchot tece relevantes reflexões acerca daquilo que poderia se configurar como o espaço literário. Sua abordagem percorre múltiplos caminhos que vão da literatura experimental de Mallarmé à poética do sagrado de Hölderlin. No entanto, esse "espaço literário" pode ser alargado, uma vez que as novas tecnologias trazem para os estudos de literatura 
outras possibilidades de criação poético-literária. Assim, ao longo deste escrito, tentaremos delinear um pouco do que se tem discutido em torno das relações entre literatura e mídia digital, isto é, acerca do fazer poético nesse novo espaço, que é o digital. Um espaço sobre o qual ainda há muito por dizer, apesar de já haver um número significativo de pesquisadores que têm se dedicado a pensar tais relações. Conforme observa Pedro Barbosa, a dificuldade em delimitar esse campo de estudos encontra-se presente, porque ele ainda está em fase de consolidação. Por ora, a "certeza" da qual dispomos é que mesmo em meio a tantas denominações, muitas confusas e até equivocadas, é que esse novo espaço literário-digital parece trazer inscrito em sua origem as marcas de um novo experimentalismo literário (uma renovação do experimentalismo literário? Questiona Pedro Barbosa), novas noções de temporalidade e espaço ${ }^{1}$ e, por conseguinte, também uma via para se discutir os caminhos da literatura e a tão propalada questão dos gêneros, que desde Aristóteles ainda permanece como uma questão que encerra muitos problemas.

E quando usamos designações ainda mal estabilizadas, como sejam Literatura Gerada por Computador, Literatura Informática, Literatura Algorítmica, Literatura Potencial, Ciberliteratura, Literatura Generativa, Hiperfiç̧ão, Texto Virtual, Geração Automática de Texto, Poesia Multimédia ou Poesia Animada por Computador, estaremos a falar de novos gêneros literários, de novas estruturas textuais ou de uma nova corrente literária? Que se trata de uma nova corrente artística, abrangendo a nível mundial quase todas as artes - desde a música às artes visuais, passando mesmo pelo cinema - disso parece não restar dúvida. Seja como for, poder-se-á falar aqui, sem pretender com isto abrir polémica, de uma renovação do "experimentalismo literário".

Não obstante, mesmo com a produção de importantes trabalhos que dialogam com a questão literatura-mídia digital, ainda há bastante desconfiança em torno desse novo saber que se constrói no espaço digital. Há os que temem,

1. Beatriz Resende, no suplemento "Prosa online", argumenta que toda literatura postada em blogs tende a uma neutralização do tempo e do espaço. Texto disponível em: <http://oglobo.globo.com/blogs/prosa/ post.asp?cod_post=45546>. Acesso em: 21 nov. 2011.

2. BARBOSA. A renovação do experimentalismo literário na literatura gerada por computador. Disponível em: <http://www.pedrobarbosa.net/ artigos_online-pdf/lgc-artigo.pdf >. Acesso em: 21 nov. 2011. 
inclusive, pela extinção do livro impresso, outros que acreditam na subordinação do humano ao maquínico e há aqueles que julgam que esse novo saber, de alguma forma, tende a aprisionar o homem e limitar sua capacidade de pensar, sua inventividade e criatividade, transformando-o em um autômato do saber. Mas tal temor diante do novo não é novidade e muito menos limita-se ao espaço digital. Pierre Lévy, em Cibercultura, lembra-nos de que muitas manifestações artísticas que surgiram ao longo da história, em um primeiro momento, foram vistas como verdadeiras ameaças à cultura. O cinema é um desses exemplos. Atualmente visto como uma forma de arte, também em seu nascimento foi visto com desconfiança por parte de intelectuais "bem-pensantes", que vislumbravam na sétima arte um meio de empobrecer o intelecto daqueles que se rendiam aos encantos da grande tela. Mas por que razão parece tão difícil conceber que cada época faz uso de técnicas e de tecnologias que se encontram à disposição dos saberes? Antônio Risério observa que toda manifestação artística, em seu tempo, teve à sua disposição uma ou outra técnica específica, desde o milenar papiro até o computador de hoje. E, cada uma, à sua maneira, deixou sua digital nas produções artísticas engendradas nas diferentes épocas. Uma ou outra técnica serviu de substrato ao fazer poético, assim como hoje temos à nossa disposição o saber "internético" sobre o qual fala o professor Alckmar Luiz dos Santos, da Universidade Federal de Santa Catarina:

O saber internético [...] não deve ser confundido com pressa, como também não pode ser confundido com totalidade ou infinitude: ele deve ser capaz de gerar diferentes velocidades e sincronias, a partir de diversas pessoas envolvidas e apostando, sobretudo, numa atitude em que são os instrumentos informáticos que se põem a nossa disposição e não nós que nos colocamos à disposição deles. ${ }^{3}$

Como pensar o fazer poético diante de outros suportes que geram temporalidades, linguagens e espaços outros? Decerto são questões que nos possibilitam uma reflexão fecunda acerca dos caminhos da literatura, uma vez que o que está em jogo nesse novo espaço de saber é a criação poética, a questão da autoria, a relação mais interativa com o leitor e até a possibilidade de construção de uma nova crítica e postura acadêmica. A professora e crítica literária, Leda

3. SANTOS. O saber internético. Disponível em: <http://www.cce.ufsc.br/ $\sim$ nupill/hiper/saber.html>. Acesso em: 21 nov. 2011. 
Tenório da Motta, ao falar desse novo tempo de produção e recepção do texto literário, não hesita em dizer que estamos na era de um renascimento da crítica, por meio, sobretudo, do crescente florescimento das revistas literárias digitais. E nessa linha de raciocínio também podemos pensar em uma certa democratização do saber, uma vez que os meios digitais, de maneira inconteste, colocam-se bem mais acessíveis à circulação do conhecimento seja literário ou de outra ordem. Para Leda Tenório:

Inegavelmente, a web está permitindo às revistas literárias, que aí florescem com a maior qualidade, envolvendo artistas e scholars que pensam fora da sombra das autoridades acadêmicas instituídas, e jornalistas que não são aqueles 'nadólogos' de que falava Balzac na sua corrosiva Monografia da imprensa parisisense, exponenciar as possibilidades desde sempre abertas para a crítica pelo lugar da revista. Há uma renascença da crítica aí, sim. ${ }^{4}$

Mas não são apenas as revistas literárias digitais que têm aberto novos caminhos à literatura. Não nos esqueçamos que muitas produções literárias contemporâneas da nova safra de escritores e poetas contemporâneos encontram nos blogs o espaço para a circulação de seus textos, uma "ruptura com o suporte", como observa Beatriz Resende. Alguns publicam primeiro suas obras nos blogs para depois partirem para o mercado editorial impresso. A escritora Ana Paula Maia, por exemplo, deixou, por um bom tempo, disponíveis em seu blog, os doze capítulos que compõem sua obra Entre rinhas de cachorros e porcos abatidos, para só depois publicá-la no suporte de papel. Maira Parula também publica em seu site de literatura - "Prosa caótica" - alguns de seus textos, bem como de outros autores. Beatriz Resende nos lembra de que a ruptura com os suportes não é exclusividade da literatura e há muito já atingiu outros campos das produções artísticas, como o teatro e as artes plásticas. No entanto, no caso da literatura, conforme argumenta Beatriz Resende, essa ruptura está se dando com aquilo que parecia ser sinônimo de sua condição básica de existência: o suporte papel, ou seja, o que permitia que a literatura tomasse forma. Mas essa literatura sem papel seria uma ameaça à perenidade das obras? Ou seria sinônimo de publicações de

4. мOTTA. Uma arqueologia da cibercultura e da cibercrítica: estudo sobre as antecipações vanguardistas das infopoéticas contemporâneas. Disponível em: <http://www.pucsp.br/ ltmotta/pdf/projeto_arqueologia_ciber literatura.pdf $>$. Acesso em: 21 nov. 2011. 
textos sem muito critério de qualidade, uma vez que a facilidade para a divulgação dos textos é ilimitada? Ainda é cedo para dizer. Mas não é cedo para dizer que essa nova relação de produção e recepção já está escrita na história da literatura recente. O cenário literário, inegavelmente, já foi alterado quer no plano da crítica, quer no plano da produção, quer no plano da recepção, quer no plano da circulação das produções literárias. Ainda é Beatriz Resende, uma grande pesquisadora e incentivadora desse novo saber quem argumenta que:

A crítica literária não pode mais ignorar esse fenômeno, mesmo porque os próprios autores passam a exercer o papel de críticos, comentando uns aos outros. As editoras tradicionais, aquelas que continuam produzindo livros em papel, descobrem que podem pescar na rede novos autores, perceber novas tendências, avaliar com facilidade novas práticas literárias e, ao mesmo tempo, verificar a repercussão que textos e autores têm junto a esse novo tipo de leitor, o que recebe de imediato, em casa, a qualquer momento, um produto literário similar ao que elas levam tanto tempo em preparar, imprimir, divulgar, lançar e vender.

José Saramago manteve um blog por mais ou menos um ano - "O caderno" - e reconhecia que esse novo espaço de criação pode se configurar como um importante incentivo à escrita, à criação, mas também vislumbrava nesse espaço um local para a produção de textos de qualidade duvidosa, pois muitos não se preocupam com o estilo, com a criatividade. Talvez, no caso da produção poética veiculada nos blogs a desconfiança também persista, porque inicialmente eles surgiram como um espaço de registros de atividades diárias, uma espécie de substituto do antigo diário de papel. No entanto, há muito que os blogs deixaram de ter essa tradução limitada e se transformaram também em um espaço para reflexões de importantes intelectuais e pesquisadores, bem como para a produção poética de muitos escritores e poetas, sobretudo os da nova safra, conforme já o dissemos. É claro que por seu caráter democrático e interativo, há aqueles que utilizam-no para o relato de experiências cotidianas sem grande relevância para reflexões literárias ou de qualquer outra ordem. Mas, como no caso da televisão, diabolizada por muitos, há a opção do zapping e com os blogs também não é diferente. É possível selecionar a leitura que mais atenda a nossos anseios. Sabemos

5. RESENDE. Contemporâneos: expressões da literatura brasileira no século XXI, p. 136-137. 
que há textos postados nos blogs que estão longe de alcançar o estatuto de produção literária, mas isso não se deve ao suporte, mas sim, ao produtor de textos. Até por que, bem sabemos que há poemas, romances, contos publicados no suporte papel e que são de qualidade duvidosa. Também não acreditamos que seja producente para os estudos de literatura tentar apagar as diferenças que existem entre o suporte papel e o suporte digital ou ficar contabilizando os ganhos de um ou perdas de outro ou simplesmente substituir um pelo outro como o fuzil substituiu o arco. Cada um possui suas especificidades, suas dimensões de plurissignificação literária que não se excluem. E a literatura é o espaço aberto a essas reflexões. Como muito sabiamente afirma Ítalo Calvino: "A função da literatura é a comunicação entre o que é diverso pelo fato de ser diverso."

Quiçá o espaço digital visto como um espaço de produção poética ainda seja visto com certa desconfiança e receio, porque ele traz fortemente impresso as marcas do experimentalismo. Mas a literatura já convive há muito com experimentalismos, num período bem anterior ao boom dos computadores. Podemos aqui recuperar vários exemplos de obras que fizeram uso do suporte papel e que não foram menos experimentais que as obras produzidas em espaço digital. Mallarmé é o nome que vem à mente de pronto, mas não nos esqueçamos, por exemplo, das atividades desenvolvidas pelos membros do OULIPO - Ouvroir de Littérature Potentielle (Oficina de Literatura Potencial) - grupo literário surgido na França, na década de sessenta. Tendo à frente o escritor e poeta afeito à linguagem matemática, Raymond Queneau, o OULIPO reinventou a literatura, os processos de criação, enfim, o fazer poético. Os aforismos gerados automaticamente pelo sintetizador automático de textos, o sintext - $W$ de Pedro Barbosa já haviam sido experimentados pelo OULIPO, conforme pode ser visto, por exemplo, na produção poética de Marcel Bénabou, na qual o poeta, a partir das palavras "arte" e "acaso" engendra um poema explorando as múltiplas possibilidades de combinação entre os dois vocábulos.

No caso do sintext - $W$ de Pedro Barbosa, as palavras multiplicam-se indefinidamente a partir de um programa de computador, entretanto não podemos deixar de registrar que experiências dessa natureza, que exploram o máximo da

6. CALVINO. Seis propostas para o próximo milênio, p. 58.

7. No Brasil esse experimentalismo literário deu seus primeiros passos, ainda no suporte papel, com as produções poéticas engendradas pelos poetas concretistas, sobretudo, os irmãos Campos. 
potencialidade da linguagem, já haviam sendo desenvolvidas. Queneau, por exemplo, em Exercícios de estilo, conta de noventa e nove formas diferentes a história de um estranho que ele vê duas vezes em um mesmo dia, e em outra produção - Cem milhões de poemas - Queneau, por meio de uma série de sonetos, mostra que combinados entre si eles podem gerar um imenso número de poemas distintos.

A cada primeiro verso (há dez deles) pode-se fazer corresponder dez segundos diferentes versos; há portanto cem combinações diferentes dos dois primeiros versos; se acrescentarmos a isso o terceiro, teremos o resultado enunciado acima [dez elevado à décima potência]. Se contarmos quarenta e cinco segundos para ler um soneto e quinze segundos para mudar as tiras, numa base de oito horas por dia, duzentos dias por ano, teremos mais de um milhão de séculos de leitura, lendo o dia todo, ao longo de trezentos e sessenta e cinco dias por ano.

Outro membro do OULIPO, Georges Perec, em A vida modo de usar, também potencializa ao máximo o experimentalismo literário e a possibilidade de interatividade com o leitor. O texto se constrói com base na combinação da história narrada com os cômodos de um edifício e um tabuleiro de xadrez. Cada cômodo recebe um número de 1 a 99 e, como sugestivamente observa a pesquisadora Cláudia Amigo Pino, o cômodo de número 100 existe, mas não entra na história, "para dar uma espécie de brecha ao leitor". ' O leitor também pode habitar um cômodo, ser uma peça no xadrez. Enfim, uma forma de integração do leitor à obra, em que os próprios textos se oferecem como reflexão sobre seu processo criativo. Roland Barthes diz-nos em Crítica e verdade que o que define quem escreve é a consciência que esse alguém tem da palavra, a maneira como quem escreve experimenta a linguagem em sua profundidade. No espaço literário-digital, bem como na poética do OULIPO vislumbramos a experiência da linguagem em sua densidade máxima. Cada ícone, cada link, cada combinação, cada jogo vocabular, cada narrativa não sequencial nos transportam a temporalidades, linguagens e espaços outros e, por conseguinte, à reflexão dos processos de emissão e recepção

8. QUENEAU, apud MOTTA. Cent mille milliards de poèmes. Disponível em: <http://www.pucsp.br/ ltmotta/pdf/projeto_arqueologia_ciber literatura.pdf $>$. Acesso em: 21 nov. 2011.

9. PINO. A ressignificação do mundo, p. 47-53. 
do texto, da figura do autor e do leitor, a construções de novos saberes, um saber "internético" em que os instrumentos computacionais se colocam à nossa disposição, até por que o poeta não é um computador e um computador não é um poeta. Por trás da máquina há um humano a governá-la, ${ }^{10}$ ou seja, trata-se tão-só de saber fazer uso criativo de recursos e procedimentos que a máquina computador pode oferecer ao poeta. Uma técnica e/ou instrumento a mais. Não é um caso de machina sapiens. Como observa Antônio Risério: "Não se trata de criar como um computador, mas de criar com. De colocar o computador a serviço da produção poética. De servir-se de seus programas para inscrever signos."

Pedro Barbosa argumenta que a ciberliteratura ou a literatura algorítmica, generativa nada mais é que a proposta de explorar todas as potencialidades da máquina computador para a produção criativa de estruturas textuais. Um diagrama criativo que, segundo Pedro Barbosa, seria composto da seguinte maneira: artista (criação) + computador (execução) = obra[s] (múltiplos).

O acto criativo cinde-se aqui sempre em dois momentos: o da concepção (humana) e o da execução (maquinal), segundo Max Bense; ou, segundo Abraham Moles, o da criação essencial ou ontológica (realizada pelo artista) e o da criação secundária ou variacional (realizada pela máquina). O artista concebe o modelo da obra a realizar (programa), a máquina desenvolve e executa as múltiplas realizações concretas desse modelo dentro de um campo de possíveis. O texto-matriz (pattern), concebido pelo autor em estado latente ou potencial, abre-se sempre a um campo de possíveis mais ou menos vasto, e tendencialmente infinito, que constituirá o conjunto dos estados textuais actualizados ou concretos. Tal campo de possíveis dará origem a um campo de leitura, o qual pode ser explorado pelo próprio autor, que nele irá colher e seleccionar o(s) texto(s) a apresentar ao leitor, mas pode também ser explorado directamente pelo próprio leitor, dependendo isso de quem use no computador o programa criado. ${ }^{12}$

10. Antônio Risério nos lembra da etimologia da palavra "cibernética", que deriva do grego Kybernetiké: pilotar, governar.

11. RISÉRIO. Ensaio sobre o texto poético em contexto digital, p. 203. (grifos do autor.)

12. BARBOSA. A renovação do experimentalismo literário na literatura gerada por computador. Disponível em: <http://www.pedrobarbosa.net/ artigos_online-pdf/lgc-artigo.pdf>. Acesso em: 21 nov. 2011. 
Desse modo, parece muito claro que a ciberliteratura não tem por objetivo "matar" o poeta e sua criação artística em favor da máquina. Ao poetaartista cabe a criação, ao computador, um meio para a execução do processo criativo, um meio que permite um alargamento desse processo criativo através de programas computacionais, bem como uma participação mais efetiva do leitor, que passa à função, digamos, de coautor do texto digital, uma vez que há programas com inúmeros recursos que exigem do leitor que ele interaja com a obra um pouco mais além que a leitura simplesmente de um texto impresso, pois diante de um poema digital, o leitor entra em contato com vários signos outros: o verbal, o sonoro, o visual. É um grande diálogo com outros saberes: "A poesia digital é hiper e intertextual. [...] Dialoga com as artes plásticas, visuais, sonoras, teatrais, fotográficas, cinematográficas, videográficas, holográficas, etc." ${ }^{13}$

Muitas produções poéticas digitais só se realizam se o leitor-operador der o seu click, usando, às vezes, uma sequência previamente indicada ou em outros textos, a sequência que desejar. Quiçá, seja essa também uma das razões pelas quais Pierre Lévy tenha afirmado que o leitor em tela é mais ativo que o leitor de textos cujo suporte é o papel: "Ler em tela é, antes mesmo de interpretar, enviar um comando a um computador para que projete esta ou aquela realização parcial do texto sobre uma pequena superfície luminosa." ${ }^{14}$ Vários sentidos precisam ser acionados ao mesmo tempo para que a obra se concretize. Desse modo, parece-nos ficar bastante evidente que algumas noções tradicionais daquilo que convencionalmente envolve o circuito literário são colocadas em xeque, sobretudo, no que diz respeito à relação triádica autor-texto-leitor, há tanto discutida pelos estudiosos de literatura. Para Antônio Risério, a grande mudança provocada pelas produções poéticas digitais se dá mesmo no que concerne à estrutura das obras em questão e às relações do receptor ${ }^{15}$ com elas.

12. BARBOSA. A renovação do experimentalismo literário na literatura gerada por computador. Disponível em: <http://www.pedrobarbosa.net/ artigos_online-pdf/lgc-artigo.pdf $>$. Acesso em: 21 nov. 2011.

13. ANTONIO apud SAMUEL. Novo manual de teoria literária, p. 210.

14. LÉVY. O que é o virtual?, p. 40.

15. Talvez fosse de grande valia um estudo mais acurado que se dispusesse a investigar quais as reais implicações das produções digitais na teoria da estética da recepção. 
Martha Carrer Cruz Gabriel ${ }^{16}$ explora sobremaneira a interatividade com o leitor, permitindo a ele selecionar e ordenar palavras e versos, como pode ser observado, por exemplo, nos poemas digitais - "Reflexões no vazio" e "Ampulhetra". No primeiro, há inicialmente uma sequência de versos que, à medida que o leitor-operador dá um click, altera, coparticipa da criação poética e experimenta outras possibilidades de versos e pode fazer sua própria reflexão acerca do vazio. No segundo, dentro de uma ampulheta há várias letras que caem aleatoriamente mediante o contato e certo desespero do leitor, uma vez que raramente se consegue construir uma palavra que possua algum significado coerente. Mais ou menos como a sopa de letrinhas com a qual Drummond, no poema "Sentimental", tenta desesperadamente escrever o nome da mulher amada, mas não consegue encontrar a letra que faltava. O sistema aleatório de "Ampulhetra" corrobora que letras e palavras podem ser combinadas entre si numa infinidade de maneiras e a forma poema pode sair dessa combinação múltipla e infinita.

O poeta Sérgio Monteiro de Almeida, ${ }^{17}$ no poema digital "Almas II" faz uso de vários slides de powerpoint e com apenas um verso - "Tenho diversas almas" - e uma infinidade de cores que passam pelo preto, vermelho, verde, branco, entre outras, permite que o leitor vá projetando os slides e quiçá, pelas diferentes nuances de cores, vá encontrando a sua, pois o décimo sexto slide encontra-se vazio, para que o leitor preencha-o, a exemplo do que fez Perec com o centésimo cômodo de seu edifício-tabuleiro. Trata-se de uma produção poética demasiado simples, que explora os recursos primários dos programas de computador, mas que inegavelmente inquieta e causa um mal-estar no leitor-operador que não consegue ficar indiferente à cartela de cores proposta por Sérgio Monteiro de Almeida. Fundo e forma se fundem. É o que também podemos vislumbrar no "Poema-bomba", de Augusto de Campos. O texto, em pedaços, é projetado em um fundo vermelho sangue misturado a um alaranjado fogo e acompanhado de ruídos confusos explode na tela. Quem sabe não poderíamos ver nas produções poéticas digitais um maior empenho em diminuir as fronteiras que ainda existem entre fundo e forma? É claro que ao longo da história da literatura muitos se dedicaram a esse propósito sem necessariamente fazer uso de um computador,

16. Os poemas citados estão disponíveis no site: <http://www.ociocriativo. com.br/poesiadigital/poesias/index.htm>.

17. O poema citado encontra-se disponível no site: <http://www.ociocriativo. com.br/poesiadigital/poesias/index.htm>. 
como Mallarmé, o grupo OULIPO, os surrealistas, algumas produções dos poetas concretistas, mas a poética digital nos parece provocar a ruptura definitiva, apesar de sabermos o quanto o termo "definitivo" pode ser complexo.

Antônio Risério argumenta que com o computador, nós leitores, encontramo-nos diante de uma variedade sem fim para redesenharmos os textos que já se consagraram em um determinado suporte e gênero. Lembra que podemos, por exemplo, colocar em prosa as Cartas chilenas ou dispor em versos Grande sertão: veredas. De fato, as possibilidades nos parecem mesmo infindáveis. Rui Torres, poeta português, inspirado pela narrativa de Clarice Lispector: o conto "Amor", produz o poema hipermédia - "Amor de Clarice" - transformando em versos a história da personagem Ana. Uma produção poética composta por vídeos, declamação e animação dos versos, antes lidos na forma de prosa.

\section{$[\ldots]$}

Mas Ana tem um lar

Ana olha o antes

E a Ana tem um lar

Há uma perigosa hora na tarde

Nessa hora procura Ana atravessar o amor

Olha Ana profundamente como se olha o que nos vê

E uma expressão há muito não usada ressurge em Ana

Quebraram-se os ovos

E a rede $[\ldots]^{18}$

Conforme já foi dito, apesar de haver um número considerável de estudos que dialogam com a temática das produções digitais, ainda há um longo caminho a ser percorrido, sobretudo, por se tratar de um campo que se encontra em fase de consolidação, como observou Pedro Barbosa. As vias de acesso para se pensar o espaço literário, o espaço digital, as temporalidades, o fazer poético e o diálogo entre eles são múltiplas. É uma rede que se abre a muitas tessituras. Dentro deste espaço, qualquer fio que puxarmos, decerto, permitirá o tecer de significativas reflexões para o pensamento contemporâneo e para nossa prática de ensinantes e de pesquisadores de literatura. Enfim, quais implicações esses novos modos de tecer as narrativas e os poemas trazem para a literatura? Essa é a questão. No

18. TORRES. Amor de Clarice. Disponível em: <http://telepoesis.net/ amorclarice/amor.html>. Acesso em: 21 nov. 2011. 
entanto, nunca é demais afirmar que não basta uma mudança de suporte. Não se trata da mudança pela mudança. De pouco adianta mudar o suporte, se nosso olhar não seguir o curso de tal mudança. A "máquina do mundo" está aos nossos pés, saber conduzi-la, eis a grande questão!

\section{Literature and Digital Space: Poetic Dialogues}

Abstract: This article aims to establish a reflection on the relations between literature and new technologies, particularly the literature produced in the digital space, in its project of reinvention of literary language, in which resources such computer programs are part of the creative process.

Key-words: literature, dialogue, digital.

$$
\text { Referências }
$$

ALMEIDA, Sérgio Monteiro de. Almas II. Disponível em: <http://www.ociocriativo. com.br/poesiadigital/poesias/index.htm>. Acesso em: 24 jul. 2011.

ANDRADE, Carlos Drummond de. Sentimental. In: Poesia completa. v. único. Rio de Janeiro: Nova Fronteira, 2007.

ANTÔNIO, Jorge Luiz. In: SAMUEL, Rogel. Novo manual de teoria literária. Petrópolis: Vozes, 2007.

BARBOSA, Pedro. A renovação do experimentalismo literário na literatura gerada por computador. Disponível em: <www.pedrobarbosa.net/artigos_online-pdf/lgcartigo.pdf $>$. Acesso em: 24 jul. 2011.

BARTHES, Roland. Crítica e verdade. Tradução de Leyla Perrone-Moisés. São Paulo: Perspectiva, 1999

BÉNABOU, Marcel. A arte e o acaso. Cult. São Paulo, n. 52, p. 53, nov. 2001.

BLANCHOT, Maurice. O espaço literário. Tradução de Álvaro Cabral. Rio de Janeiro: Rocco, 1987.

CALVINO, Ítalo. Seis propostas para o próximo milênio. Tradução de Ivo Barroso. São Paulo: Companhia das Letras, 2002

CAMPOS, Augusto de. Poema-bomba. Disponível em: <http://www2.uol.com.br/ augustodecampos/poemas.htm>. Acesso em: 24 jul. 2011.

GABRIEL, Martha Carrer Cruz. Reflexões no vazio. Disponível em: <http:// www.ociocriativo.com.br/poesiadigital/poesias/index.htm>. Acesso em: 24 jul. 2011.

GABRIEL, Martha Carrer Cruz. Ampulhetra. Disponível em: <http://www.ociocriativo. com.br/poesiadigital/poesias/index.htm>. Acesso em: 24 jul. 2011. 
LÉVY, Pierre. Cibercultura. Tradução de Carlos Irineu da Costa. São Paulo: Ed. 34, 1999.

LÉVY, Pierre. O que é o virtual? Tradução de Paulo Neves. São Paulo: Ed. 34, 1996.

MOTTA, Leda Tenório da. Uma arqueologia da cibercultura e da cibercrítica: estudo sobre as antecipações vanguardistas das infopoéticas contemporâneas. Disponível em: <http://www.pucsp.br/ ltmotta/pdf/projeto_arqueologia_ciberliteratura.pdf>. Acesso em: 24 jul. 2011.

PEREC, Georges. A vida modo de usar. São Paulo: Companhia das Letras, 2009.

PINO, Cláudia Amigo. A ressignificação do mundo. Cult. São Paulo, n. 52, p. 46-53, nov. 2001.

QUENEAU, Raymond. Exercícios de estilo. Rio de Janeiro: Imago, 1995.

QUENEAU, Raymond. Cent mille milliards de poèmes. In: MOTTA, Leda Tenório da. Uma arqueologia da cibercultura e da cibercrítica: estudo sobre as antecipações vanguardistas das infopoéticas contemporâneas. Disponível em: <http://www.pucsp.br/ $\sim$ ltmotta/pdf/projeto_arqueologia_ciberliteratura.pdf>. Acesso em: 24 jul. 2011.

RESENDE, Beatriz. Contemporâneos: expressões da literatura brasileira no século XXI. Rio de Janeiro: Casa da Palavra, 2008.

RESENDE, Beatriz. Não fecha os olhos esta noite, de Maira Parula. Disponível em: <http://oglobo.globo.com/blogs/prosa/post.asp?cod_post=45546>. Acesso em: 21 nov. 2011.

RISÉRIO, Antônio. Ensaio sobre o texto poético em contexto digital. Salvador: Casa de Palavras, 1998.

SANTOS, Alckmar Luiz dos. O saber internético. Disponível em: <http://www.cce.ufsc. br/ nupill/hiper/saber.html>. Acesso em: 24 jul. 2011.

TORRES, Rui. Amor de Clarice. Disponível em: <http://telepoesis.net/amorclarice/ amor.html>. Acesso em: 24 jul. 2011. 